\title{
Human capitalisation in activation : Investing in the bodies, selves and skills of unemployed youth in Finland
}

\section{Paju, Elina}

2020

Paju , E , Näre , L , Haikkola , L \& Krivonos , D 2020 , ' Human capitalisation in activation : Investing in the bodies, selves and skills of unemployed youth in Finland ', European Journal of Cultural and Political Sociology , vol. 7 , no. 1 , pp. 7-28 . https://doi.org/10.1080/23254823.2019.1689834

http://hdl.handle.net/10138/331750

https://doi.org/10.1080/23254823.2019.1689834

unspecified

acceptedVersion

Downloaded from Helda, University of Helsinki institutional repository.

This is an electronic reprint of the original article.

This reprint may differ from the original in pagination and typographic detail.

Please cite the original version. 


\title{
Human Capitalisation in Activation: Investing in the Bodies, Selves and Skills of Unemployed
} Youth in Finland

\begin{abstract}
This article analyses how processes of 'human capitalisation' work in various labour-market activation services aimed at young people in Finland. Drawing on multi-site ethnographic research on activating workshops, public employment services, and career counselling for youth in the Helsinki metropolitan region of Finland in 2014-2016, we trace sites and instances of human capitalisation. Capturing processes through which previously non-economic areas of life become economised, human capitalisation marshals abilities, skills, knowledge and a consumeristic understanding of self-responsibility. Its promise is a more flexible workforce that can be adjusted to the varied demands of the labour market in the future. Taking a Foucauldian approach to governmentality, our research demonstrates that activation practices focus on generating a form of human capital that enhances a particular relation to and understanding of one's self, body and skills.
\end{abstract}

Key words: unemployed youth, labour market activation, human capital, human capitalisation, Finland, youth employment, NEET

\section{Introduction}

In this article we examine how 'human capitalisation' is enacted in activation measures directed at young people outside education and employment. 'Human capitalisation' refers to the neoliberal ideas of Chicago-School economics, according to which neoclassical economics can be inserted into domains of social life beyond the purely economic. The economy thus comes to encompass human action in its entirety (Davies, 2014; Foucault, 2010; Lemke, 2001). This model and theory of human capital rests on the premise that human behaviour is statistically predictable (Davies, 2014; Newheiser, 2016), and, therefore, that the relationships of (economic) investments to economic outcomes are measurable (Woronov, 2012). Moreover, human capitalisation contributes to creating a special relation to oneself: namely, as an entrepreneurial self (McNay, 2009; Scharff, 2016). ${ }^{1}$ Our findings demonstrate that this economic rationale is obscured in encounters with young clients yet in the practices in which they take part it is nonetheless present.

Our analysis participates in the discussion around human capitalisation inspired by Foucault (2010) and thus our usage differs from the economically defined view of human capital as a tool for 
shaping practices and agendas inside education, health care and management. In short, human capital is a central strategy of governance (cf. Adamson, 2009). Moreover, we understand human capitalisation according to Foucault's (2010) interpretation: as an expression of neoliberal governmentality.

Research literature on human capitalisation has tended to focus either on theoretical conceptualisations (Bowsher, 2018; Gane, 2014; Lemke, 2001; McNay, 2009) and/or on the policy side of human capitalisation (Adamson, 2009; Bengtsson, 2011; Brown, 2015; Prasad, 2009) rather than on grass-roots-level practices and experiences. Existing research has analysed labour market activation as the production of new forms of governance through the repertoires of governmentality, empowerment and individualisation (Boland, 2016; McDonald \& Marston, 2005; van Oort, 2015) and demonstrated that differing policy and management contexts shape street-level practices and their aims (Brady, 2011; 2018). However, significantly less is known about the implementation of labour activation at grass-roots level through frontline practices from the perspective of human capitalisation. This article contributes to the understanding of human capitalisation as it works on the practices and experiences of those targeted by activation measures.

The article is based on multi-sited ethnographic research on activating measures directed at young people outside education and employment, which followed young clients through diverse encounters, practices, courses and events. We explore the ways in which human capitalisation penetrates knowledge of the self, enhances investments into one's body and emphasises the cultivation of general and transferable skills, rather than specific skills and techniques. Examining young people's reactions to these measures, this study investigates the emergence of human capital in practice and contributes to the evolving discussion on living neoliberal subjectivity (Scharff, 2016).

The cases studied fall under the labour-market activation measures directed at under-29-year-old young people in Finland. Young people, a target group for these measures, present an interesting case for the study of activation due to their transitional position in the life-course, between compulsory education and work. This threshold position creates the perception of youth as a group at risk (Folles $\varnothing, 2015$; Kelly, 2006). Based on our data, we propose that young clients encounter requirements, expectations and ideals of human capitalisation in interactions with career counsellors and case-workers in employment offices and in the various pre-planned activities and practices aimed at them in activating workshops. We show how the distinct logic behind human capital, which invites and constrains individuals to 'cultivate living capacities within themselves' (Binkley, 2014, p. 4), permeates young people's minds and bodies, affecting their relations to their selves, 
bodies and capabilities. Training the self to regard oneself as an enterprise (cf. McNay, 2009) demands a specific set of practices and rationales. Our analysis also demonstrates how the enactment of human capitalisation is a complex, not a straightforward, process. We show too that the young clients may not always comprehend or adopt the ideal of self-cultivation as capital proposed by the agents working with them. Thus, our analysis touches upon the ways in which the young people see themselves in relation to such measures and how they adjust or react to them, in short, how they are subjected to them (Foucault, 1985). In what follows we, first, briefly introduce the current discussion on labour market activation focusing on the concept of human capitalisation, which is our theoretical and analytical tool. We then introduce the multi-sited ethnographic research on which our discussion is based, followed by a presentation of our research findings on how human capitalisation is enacted in grass-roots encounters in activation services. We conclude by discussing some of the contradictions in the process of human capitalisation in youth activation.

\section{Analysing labour market activation from a human capital perspective}

Employment activation is a form of dispersed governing (Clarke, 2005) that takes place in different sites. Activation aims to produce labour-power for insecure labour markets and to re-commodify labourers (Greer, 2016; Wiggan, 2015). The qualitative research literature on labour activation has primarily analysed activation in terms of the production of new forms of governance and neoliberal subjectivities (Boland, 2016; Darmon \& Perez, 2010; Dean, 1995; McDonald \& Marston, 2005; Sharone, 2007; van Oort, 2015). Viewed from a Foucauldian perspective of governmentality, as an activity aimed at shaping the conduct of a person or a population (Gordon, 1991), job-seeking services constitute subjects by encouraging job-seekers to re-invent themselves through discovering skills, becoming the subjects of reflection and working on better, more employable selves (Boland, 2016).

The governmentality approach has illustrated how job-seeking agencies turn unemployed citizens into active job-seekers and enterprising selves (Rose, 1999) with new moral identities (McDonald \& Marston, 2005; van Oort, 2015), invited to re-invent their selves through self-improvement, control of negative emotions related to unemployment (Arts \& van den Berg, 2018; Boland, 2016; Smith, 2010) and even re-creation of their characters (Hughes, 2005). The activation measures reflect a wider contemporary ethos concerning work: the individual is constructed through work, which is 
assumed to play a role in the production, discovery and experience of the self (Rose, 1999). Key government technologies in the area of unemployment are case-management and individualised services for the unemployed.

State job-seeking agencies and welfare-to-work services have been demonstrated to act as engines that produce self-help ideologies of individual control and self-sufficiency, and aim to create flexible, productive, disciplined job-seekers. Boland (2016) has argued that social welfare offices articulate the language of selling one's experiences and skills, which involves taking oneself as an object of reflection. Activation is dependent on wider ideologies concerning its target groups, which in turn affect the perceived benefits of street-level measures and services. Brady (2018) has recently analysed how these ideologies shift in street-level practitioners' views over the course of time and how, consequently, the target groups for activation services are constituted accordingly. The governance in labour activation is thus a specific neoliberal governance. This type of governance not only concerns the sphere of working life but encompasses life itself. As poignantly stated by Binkley (2014, p. 72), neoliberal governance is about 'making live', which can also be seen in the central concept on which our analysis rests: human capitalisation.

Human capitalisation stems from the notion of human capital, developed by Chicago School economists, particularly Theodor W. Schultz and Gary S. Becker, to measure the rates of return from investments in education. However, the concept was quickly expanded beyond the field of the economics of education to include various factors that might affect human capital, ranging from innate factors (such as genetic background) to contextual (such as social milieu and family background) and collateral (such as physical and psychological capital) factors (Feher, 2009). Human capital is still used as an instrument to shape diverse institutional practices and agendas, such as education, migration and health care (cf. Tan, 2014), and, thus, forms a general strategy for governance (Adamson, 2009). Our analysis rests on the interpretation concerning human capitalisation proposed by Foucault (2010).

In Foucault's (2010) view, the idea of human capital forms the heart of the neoliberal ethos of the Chicago School's economic rationale (cf. McNay, 2009). The idea of human capital is best understood in relation to the Chicago School's overriding objective to eliminate the division between the social and the economic. Accordingly, the economy should encompass all of human action (Lemke, 2001). Particularly in Becker's (1962) early work, human behaviour is seen as calculable and statistically predictable. Becker dramatically extended the domain of economics to 
areas previously considered to be purely social, such as crime, family and education (Davies, 2014; Newheiser, 2016). The generalisation of the economic domain served two objectives: first, to analyse non-economic spheres using economic categories and, second, to evaluate governmental practices using economic concepts (Lemke, 2001; McNay, 2009).

Human capital is inseparable from the person who possesses it because it consists of abilities, skills and knowledge (Lemke, 2001). Human capitalisation encompasses a range of social relations ranging from education, genetics and migration to the most intimate relationships (McNay, 2009). Reflecting this all-encompassing nature of human capitalisation, contemporary research following Foucault's interpretation has scrutinised such areas as education (Woronow, 2012), including career counselling (Bengtsson, 2011) and higher education (Adamson, 2009; Brown, 2015), politics (Brown, 2015), credit and debt (Bowsher, 2018), positive psychology in labour markets (De La Fabián \& Stecher, 2017) and drug testing by Euro-American companies in colonialised societies, where the simple vitality of the human body is counted as human capital (Prasad, 2009).

Bowsher $(2018$, p. 4) has aptly described the relation of the neoliberal subject to human capital: 'When figured as a portfolio of human capitals, the subject becomes an enterprise who makes investments in him/herself to compete within the market and realize profits.' The notion of human capital is linked to the understanding of self as an enterprise (Foucault, 2010; see also McNay, 2009). The idea rests on the presupposition that 'humans are, could be, or should be enterprising individuals, striving for fulfilment, excellence, and achievement' (Rose, 1998, p. 154). According to this rationale, individuals regard themselves as the entrepreneurs of their own lives and relate to their own being as a form of human capital (McNay, 2009). Consequently, labourers are no longer dependent on their employers but responsible as entrepreneurs of themselves (Lemke, 2001), and contemporary citizenship has been reduced to tending to oneself 'as responsibilised human capital' (Brown, 2015, p. 211). When analysing human capitalisation, Foucault does not pay attention to how individuals react to the strategies, practices or rules concerning it. The logics of adjusting to rules can be found elsewhere in Foucault's writings, particularly in his analysis of modes of subjection (mode d'assujettissement), which refer to, in his words (1985, p. 27): 'the way in which the individual establishes his relation to the rule and recognizes himself as obliged to put it in practice.' In our analysis, we explore modes of subjection of young people in the grass-roots implementation of human capital.

\section{Data and methods}


This article is based on a joint, multi-site ethnographic research project investigating the question of youth employment within the network of governmental, municipal and third-sector institutions involved in employment and activation services for young people outside education and employment, and considered to be at risk. A multitude of institutional agents work on, or activate, the young person left outside education and employment.

These services and measures have been implemented in Finland since 1993, when sanctions for non-compliance with employment authorities were introduced in labour market legislation. In 2001, activation measures were extended to social assistance beneficiaries, and those younger than 25 years were first singled out as a target group for labour market activation with an obligation to engage in work activities. These policies paved the way for specific policies combating youth unemployment, including the Societal Guarantee for the Young in 2005 and the Youth Guarantee in 2013. They increased sanctions for non-compliance with employment authorities. Under the Youth Guarantee, a young person (16-25 years old) should be offered education, training or employment within three months of registering as an unemployed job-seeker.

At the time of the research, youth activation measures were funded by the government or local authorities and implemented through contracting services and from various non-profit and for-profit organisations. Generally, these services were not organised around performance pay and the streetlevel services had no pressures to achieve specific outcomes, such as permanent employment or educational placements for their clients (cf. Brady 2018). Since the 1990s, Finnish youth activation policy has shared a supportive and rehabilitative aim to help young people to 'command their life' (Haikkola, Näre \& Lähteenmaa 2017; Van Aerschot 2011;), since young people outside education and employment have been perceived as risky and in need of support. Thus, frontline delivery is driven by welfare conditionality (Haikkola et al., 2017).

These activation measures were aimed at young people labelled part of the statistical NEET group (Not in Employment, Education or Training; for critique, see, for example, Furlong, 2006). The activation measures studied consisted of various organisations, actors and practices. Our fieldwork showed that the practices, processes and rationales were situational, diverse, sometimes contradictory and often dependent on particular institutions and even individual employees. Our approach, therefore, recognised that policy was not simply implemented in local contexts but was 
made and remade in a network of local sites and actors within a dispersed field of power (Lipsky, 1980; Rhodes, 1997, cited in Newman, 2007).

Adkins (2012) has argued that unemployment has become productive, and activation policies have transformed the materiality of unemployment. Activation techniques require constant activity, turning unemployment from useless, purposeless time into an eventful, productive stage. We too encountered the productiveness of unemployment as multiple projects, pilots and organisations were set up and disassembled during our fieldwork. This we ourselves experienced as deeply confusing, as the field we aimed to analyse was constantly changing.

What was offered to the young unemployed person was an array of case meetings, information events, CV-writing courses, career counselling and integration courses, workshops, training and adult education programmes and work trials. Consequently, it was not possible to define a closed field of activation with clear boundaries within a specific policy programme or managing organisation. Furthermore, the measures differed in their length and intensity. Eventually, the ethnographic data we gathered during 2014-2016 in the Helsinki metropolitan area of Finland were drawn from: 1) two local Public Employment Service offices (PES); 2) a municipal youth employment counselling-service office run by the city of Helsinki (guidance); 3) two municipal youth workshops (workshop); 4) a career-counselling course organised by a private adult-education centre (career); and, lastly, 5) various educational and employment fairs and events dedicated to young job-seekers (fairs).

PES were government-run services requiring all job-seekers to register as clients to claim benefits. The main approach was a 45-minute client meeting to steer clients to services, such as guidance and workshops in our study. Guidance was a municipal, low-threshold employment-guidance service for young people established by the city of Helsinki in response to growing concern about youth social exclusion in the aftermath of the financial crisis. ${ }^{2}$ The main approach consisted of a 45 minute client meeting to assist young people individually to find jobs or study places. Both PES and guidance also offered brief training sessions on job-seeking processes and CV workshops.

Youth workshops were a form of youth work established during the 1990s in response to an economic crisis. The workshops studied were governed by the city's Education Division. The workshops resembled educational institutions and usually had a rehabilitative orientation. Workshops were full-time courses running daily for five months. The staff, including special-skills 
instructors for media, textile crafts, metal work and so on, career counsellors, and social workers were present all the time. Career counselling courses were 30-day, full-time courses. Their aim was to help young people to learn to structure their everyday lives, choose career paths and apply to study programmes and jobs. At educational fairs the young people met with educational institutions and employers.

Our ethnographic fieldwork consisted of participant observation, interviews with both youth and staff, and photographs of the research sites. Traditionally, ethnography has not been the main source of data in governmentality studies (on the benefits of combining ethnography and governmentality studies, see Brady, 2011). Our use of the concept of human capitalisation, however, stems not from a research setting based on governmentality studies, but results from our analysis of the data we collected. Our fieldwork sites differed in their concrete practices and in their duration. Consequently, finding an overriding theme that emerged throughout the data and at all sites required several analytical readings of the data. This analysis demonstrated that the dominant logic in our multi-site field consisted of the creation of the entrepreneurial self and the enactment of human capital. Thus, the notion of human capital emerged inductively during our analysis. It should be noted, however, that the logic of human capitalisation did not emerge in all the different fieldwork sites with similar intensity. Moreover, there were other rationales guiding the work of the professionals working with the youth, too. The logic of human capitalisation was most clearly present in the youth workshops. Our analysis grew into a theoretically inspired reading examining the instances, encounters and practices where human capitalisation could be seen to be enacted in everyday grass-roots encounters. Thus, we are not arguing that human capitalisation covers all the instances, their logics, the motives of the professionals concerned or all the strategies of the relevant institutions. Rather, with the aid of this concept we are reading together a logic that is dispersed among the practices the young people encounter when in activation services.

\section{Human capitalisation in action in youth activation measures}

In this section, we first discuss investing in knowing oneself. Self-knowledge is seen as essential to the ability to manoeuvre in the employment field. The pervasive nature of human capitalisation is further analysed in the second empirical sub-section that explains how working on the body is part of the enactment of human capital. Our third empirical section demonstrates how we have moved from the appreciation of specific skills to a general frame of educability. Our analytical findings 
illustrate the 'portfolio of human capitals' (Bowsher 2018, p. 4) that are enacted in the activation measures and services for young people.

\section{Investing in knowing oneself}

The self-cultivation enhanced in the activation measures targeting the youth consists, foremost, of the skill to know oneself. Moreover, young people must also be able to express their selves to others. Self-cultivation involves a specific type of character-building: while the foundation is knowing oneself, this self should be flexible and adjustable.

The workshops present a strong case for self-cultivation and character-building as forms of human capital. Although the workshops' official goal is to secure a path for young people to either education or employment, the workshops' practical input is to adapt the young people to be 'fit for employment and education', as expressed by the workshop staff. The youth attend the workshop regularly every day according to fixed schedules. The workshops, although lasting only five months, are comparable to other forms of education - a significant area for human-capital development (Brown, 2015).

The workshop goal is explained by a staff member as to make young people able to 'answer three questions: Who am I? What can I do? And what am I capable of?' (interview, workshop, January 2016). To answer such questions the individual needs to form a special, objectifying relation to her/himself. To be able to reflect and objectify oneself is a common goal in processes of human capitalisation inside the field of education (Bengtsson, 2011), but encompasses other areas as well: as presented by Boland (2016), social welfare offices encourage their clients to form an objectified relation to themselves while selling their experiences and skills. A significant aspect of the workshops is teaching the youth not job-related skills but skills relating to human capitalisation. Knowing oneself is not a skill specific to a certain job or position but is designed to make one employable in any type of job. In the processes of human capitalisation the distinction between the spheres of production and reproduction dissolve (Feher, 2009), emphasising the expectation to maintain one's capital at all times.

The workshops' focus is on shaping the participants' lives, specifically by improving their selfknowledge and expressive qualities. Thus, they sustain and cultivate neoliberal subjectivities (cf. Scharff, 2016). The cultivation of self-knowledge does not take only verbal form. Art projects are 
commonly used here. They are seen as a good way to address the questions related to the self. As a staff member describes, a young person might sometimes answer the question of 'Who am I?' by

'...making a collage of pictures made out of textile patches. The young person chooses the patches according to the colour that s/he thinks [...] yellow now portrays and puts that in a pyramid format or something. And [...] it's easier to tell something about myself when I talk about this pyramid that has yellow and orange [patches], that I'm this sort of colourful person, and this [part] that goes up describes the fact that I have had ups and downs in my life' (interview, workshop, January 2016).

To be able to objectify oneself and one's emotions, and to be able to communicate these to others, are perceived as unquestionable goals in this extract. This requires an objectified relation to oneself, typical of human capitalisation (cf. Bengtsson, 2011; Boland, 2016). What an individual is, is interpreted as related to emotions experienced during the life-course. Interestingly, there is no value placed on specific emotions, such as happiness, which is considered important in the current labour market. De La Fabián and Stecher (2017) have argued that currently happiness forms a precondition for work and employment; it is a new form of human capital to be cultivated. Similarly, Arts and van den Berg (2018) have shown that the unemployed are actively being encouraged to control their negative emotions related to unemployment. In comparison to such findings, the Finnish activation measures in the workshops do not seek to foster happiness, but focus on the cultivation of selfknowledge. The aim is to know and assess one's emotions and one's self, and to communicate this knowledge to others.

The self in human capitalisation is never finished but always in the process of becoming (Bröckling, 2005), being constantly evaluated (Feher, 2009) and involving developing one's capabilities (Woronow, 2012), so it is no surprise that education is highly regarded in activation measures. This emphasis can also be observed in the value placed on education by the workshop staff, who maintain that, ideally, the young clients should have a place in education rather than a job once they complete the workshop period. This choice is rationalised by the types of precarious jobs available to young, uneducated people. Education, then, is seen to provide a foundation for a more sustainable career. This view illustrates the overriding ideology of human capitalisation (Woronov, 2012), which perceives investments in education and working on one's education as preparing for an unknown future. This can also be seen as an emphasis on the more general features education 
provides by training students in general attitudes, dispositions and capabilities applicable to diverse employment fields.

Self-cultivation relates not only to knowledge of oneself and one's skills but also to the self's affective capacities: the self should feel in a proper manner. The case of a meeting between a young man and a counsellor in Guidance illustrates the importance of knowing and expressing oneself accordingly. This case reveals that there are right and wrong ways to apprehend and make sense of one's feelings. A key target in this discussion is motivation and the requirement to explain it.

The client is a young man of migrant origin. It turns out that he has previously worked in a pizzeria, a typical job for his background. He does not want to do that any more but wants to change careers. The purpose of the meeting is to prepare an application template for him to use in his future job-seeking (field notes, guidance, December 2015).

This meeting focuses on how to demonstrate motivation in an application, which becomes complicated, partly due to language difficulties. Moreover, the client has difficulty understanding the purpose of determining such inner motivation, as his main reason for seeking such jobs is to no longer work in a restaurant.

They fill in the application. He tries to come up [with] how to describe why he wants a job at a warehouse. The counsellor agrees that 'this is the hard part', but 'he needs to know WHY.' It is important to justify oneself. She asks what it is that interests the client: 'What kind of work do you like?' The client does not know how to answer. She continues and asks WHY he is interested in working in a warehouse. He answers that it is because he does not want to work in a restaurant any more (field notes, guidance, December 2015).

In this example, the counsellor persistently guides the client to find his inner motivation for working in a warehouse. This work on motivation has multiple purposes. It teaches the client that it is important to be affectually oriented towards employment, to have a feeling of motivation and ambition in searching for a job. It is also crucial to bring this affectual inner self to the job-seeking process. As in the case of the collage of textile patches, young persons should know their own inner selves and be able to communicate them verbally or in some other way to others. Consequently, it is important that the client finds the right way to express his motivation by himself. The counsellor does not suggest any words to include in the application but seeks to teach the client to contemplate 
and assess his own wishes and aims. Finding the right words to describe the client's motivation to work in a warehouse takes almost the whole 45 -minute meeting. With human capitalisation as a never-completed process, these cases exemplify how young people are constantly trained to cultivate and maintain their selves as capital. Constant self-cultivation is, indeed, part of living a neoliberal subjectivity (cf. Scharff, 2016).

Living a neoliberal subjectivity (Scharff, 2016) or subjection (Foucault, 1985) to human capitalisation are by no means straightforward processes. As shown in this case, the young people at times seem perplexed as to what they are required to do and think. Rather than focusing on selfcultivation and expressing his motivations, the young client is interested in selling his labour power, which contradicts the ideology of human capitalisation. In post-Fordist systems, workers sell not their labour power but their potential and their selves as capital (Feher, 2009). These contradictions between the different aspirations of the young people and the career services result in conflicts and an inability to guide the young people, as discussed further in the next section.

\section{Investing in the body}

In this section, we illustrate that self-investment addresses not only the mental capabilities of the youth but also their bodies. In the workshops, this manifests in instructing the young people to care for their bodies, especially through proper nutrition and rest. This care of the body, in turn, is related to time management and must be completed within a certain timeframe. As an instructor advises the youth starting their workshop period:

'The working hours are from 9 am to $3 \mathrm{pm}$. Mikael says that it is good that you eat, that there are [participants] here who say that they will eat only at $4 \mathrm{pm}$ when they get home. If you don't eat, you don't have the energy to work; at 4 pm, you're feeling extremely weak. Swings in blood sugar are a severe matter' (field notes, workshop, August 2014).

Taking care of one's body through nutrition is related to the ability to perform one's job duties. However, as implied in the statement pointing out the gravity of fluctuating blood sugar levels, taking care of the body is also an investment in long-term embodied human capital, keeping it fit and adjustable for future work. Even though the advice in this example is directed to the young people individually, the concern for the health of the body can be interpreted to encompass the 
whole of the population as a potential workforce. This is the argument Prasad (2009) makes when stating that even though the notion of human capital is an individualised one, it still works on the scale of governing the whole of the population. He analyses how the lower classes of India present a business opportunity for cheap and quick drug testing for companies from Europe and the US. Prasad argues that the vitality of the population is what makes for the human capital. By paying attention to blood-sugar swings the youth in our study also take part in constituting themselves as part of the bodily competent population, vital human capital.

Investing in the body also arises in the next case of a client meeting at Guidance. As in the case in the previous section of the young man seeking to work at a warehouse, the aspirations, agendas and communication between the young person and the career counsellor conflict. In this case, Anna, who holds a vocational degree in sales, expects to find out how to pursue employment in this field while developing her language skills, which she considers important to finding employment. Rather than answering her inquiries, the career counsellor introduces her to other services:

Career counsellor: You can bring your CV next time. You can also discuss your health problems at [name of the place]. (Career counsellor gives her a booklet with information about health.)

Anna: Everything seems to be all right with my health.

Career counsellor: But call them anyway if you need something about your health, like if you get tired easily or something disturbs you. You can also do sports for free. (Career counsellor gives her another booklet with sport services). You can book courses for yourself: Taiji, Zumba ....

Anna does not look very interested as the counsellor goes on explaining sport courses. Anna says: I have a membership in a fitness club already anyway.

Career counsellor: (Simultaneously as Anna is speaking) Paintball, aqua-gym! So many different courses! You can also check your diet, your health. I strongly suggest this service to you.

Anna: Can we do my CV today?

Career counsellor: Today, we have no time for it any more, I am afraid.

They then schedule a meeting to check her CV next week. Anna leaves with a bunch of booklets about sport services, healthcare for young people and hygiene pass information. (field notes, Guidance, November, 2015). 
Anna attends a service intended to guide youth to employment and education paths through brief meetings with career counsellors. She seeks advice on how to secure employment or training that will enhance her practical, employable skills. The career counsellor's suggestions point to the importance of preserving human capital at all times through work on the body. Keeping working on the body and staying healthy are, however, also about maintaining activity, constantly preserving and reproducing one's human capital (cf. Rose, 1998). Human capital is all-encompassing (cf. McNay, 2009); in the logic of human capital, to be employable is to preserve a healthy body and an active mind. This logic is not evident to Anna, who sees finding work as a separate domain within her working life. The counsellor, however, perceives the project as a whole and connected to other domains of life, such as sport and health, as part of finding work. The counsellor encourages Anna to invest in her body; bodily capacities can be transferred to any kind of work, rather than specific skills needed for certain types of work. The human capital of homo economicus enhances its 'portfolio value in all domains of life' (Brown, 2015, p. 33). Anna and her fit body are regarded as capital for the labour market, which require constant investment and maintenance.

This case demonstrates the erosion of the distinction between the specific field of work and life in general and sheds light on the construction of long-term work on the self, body and conduct as indispensable in the making of a worker subject. The governance of human capital through labour activation serves relations of both production and reproduction (cf. Feher, 2009). Anna's encounter shows how investment in the self is simultaneously denied and encouraged. There is no time to work on her $\mathrm{CV}$, yet there is time to go through issues related to health and sports activities. Anna is required to invest in herself, but in a manner pointed towards herself. The counsellor dedicates little attention to Anna's actual unique skills, such as previous work experience and the ability to speak several languages. Like neoliberal governance in general, human capitalisation is about 'bringing to life' in a specific way (Binkley, 2014, p. 72).

\section{Investing in general skills}

In this section, we argue that rather than concentrating on specific technical skills required for particular jobs, young people are required to achieve more general skills adaptable to any job or education. The stress on general educability is illustrated by the overall purpose and practices of the youth workshops and the 30-day career counselling courses. The workshops are designed to activate the young people as employable and educatable in the future by, among other things, following 
schedules, being on time, notifying the staff of absences, and eating lunch (rather than skipping it or only drinking energy drinks) at the appointed breaktime. Managing these extra-curricular skills makes the young people fit not only for education or employment but also for citizenship in general.

The workshop staff is very conscious of the importance of the extra-curricular or in-between activities that are not the subject-matter of the thematic skills taught in the workshops.

Understanding the importance of these activities as part of self-cultivation is not self-evident. For instance, Woronow's (2012) study of Chinese vocational schools has demonstrated how the teachers do not regard such skills as being central to the curriculum. Contrary to this, the Finnish workshop staff explicitly recognises mastering such extra-curricular skills as important for the young people's future. The extra-curricular embodied capabilities and skills of enduring boredom and idleness are taught in the workshops and are applicable to any type of work or education. These are crucial in building up human capital (Woronow, 2012).

The workshops' emphasis on self-cultivation, building a special conscious relation to oneself and one's capabilities, contrasts with what the young clients themselves see as important in the workshops. They value the technical skills they learn and admire the experience of the staff teaching these specifically. These skills, however, are not as applicable to other sites of education as are more general capabilities, such as understanding the importance of being on time. Managing time and knowing how to weld can both be considered to be technical skills, but the crucial difference arises in their generalisability. As a staff member points out in relation to the thematic workshop on sound technology: the purpose of the workshop is not to direct the youth to professions in the sound technology industry but rather that 'one trainee should go into training to become a practical nurse; the other should go into vocational school to learn process technology' (interview, workshop, January 2016). Since the young clients choose workshops to attend based on their interest in the practical themes, the staff members' viewpoint can be seen as undermining the technical skills the youth are eager to learn.

The activation measures rely heavily on individuals' self-cultivation to become particular kind of selves. Neoliberal governance can be detected underlying such measures, which Binkley (2014) has explained as seeking to cultivate living capacities within individuals. The picture, however, is complicated, as the activation measures employed might restrict the possibilities of furthering a young person's educability. Such a case is illustrated in the next data-extract, from a meeting between a young woman and a career counsellor at the employment office. 
During the short meeting, [the client] constantly repeats that she wants to work as an industrial cleaner, shows the word written in her cell phone screen and even proposes and asks for other cleaning work at the airport. Instead, the counsellor signs her up in a 30-day career counselling course to 'familiarise herself with cleaning work' and 'practise her language skills' (field notes, PES, June 2014).

Employment in the Finnish labour market usually requires a degree suitable for the job at hand, posing a challenge for those who do not possess a degree at all or have no degree in the field in which they want to be employed. In these cases, the young people are actively discouraged from searching for work and instead directed to various courses. In this case, the young woman is asked to attend an introductory course to be able to attend further courses on the subject-matter. The lack of a degree is seen as a priority that overrides all concerns.

This situation places the young client in a trap. She may not sell what she has: her embodied labour power. She lacks refined bodily capital: her ability to perform cleaning duties should be standardised and certified through education. Her ability to educate herself, though, is hindered by her immigrant status, and her level of Finnish skills make it harder for her to enter training. These circumstances prevent her from harnessing her eagerness, enthusiasm and perpetual activity. In such cases, young people might paradoxically end up in an educational loop, going to course after course without increasing their likelihood of getting a job or enhancing their educability. This case also demonstrates that human capitalisation is not the only rationale at work in the different services targeted at the youth. The emphasis on different qualifications, be they educational or related to language, might in fact be contradictory or override the logic of human capitalisation.

\section{Conclusion: Becoming human capital}

In this article we have analysed labour activation measures directed at young people outside education and employment in the Finnish context. Our multi-sited ethnography has covered diverse services and measures that differ from one another in their practices as well as in their overall relation to the young people. The different agencies that we have observed might also have slightly different aims, even though they are all focused on activating young people. This article has not concentrated on the differences between the various service providers nor sought to analyse their 
possibly different views on activation. Rather, our focus has been on illustrating a rationale we found in all the different measures, that is, human capitalisation.

Our analysis illustrates how the 'portfolio of human capitals' (Bowsher, 2018, p. 4) of youth in activation services consist of three modes of investments. First, human capitalisation consists of knowledge concerning oneself. This investment emphasises self-cultivation as a knowing, feeling, expressive self. The young person needs to know who s/he is, but also how s/he feels. Hand-in-hand with knowledge of oneself goes the requirement to be able to communicate this knowledge to others. In addition to knowing and communicating, the work on the self also involves proper emotions. In our field, this consisted of the feeling of motivation. Happiness and positivity, which have been detected in research as a new form of human capital in labour markets (De La Fabián \& Stecher, 2017; see also Arts \& van den Berg, 2018; Boland, 2016; Smith, 2010), do not figure, however, in the goals for self-cultivation of young people in the Finnish activation context. The aim for self-cultivation is somewhat paradoxical: the young people are expected to know who they are and what they want to do, but this might or might not be taken into account in advice that is given to them with the intention of guiding them on their paths.

Second, human capitalisation emphasises investments in the body. This is manifested in the enhancement and preservation of the body and embodied capabilities. The maintenance of bodily capacities is reached through taking care of one's body in proper ways, that is, by healthy nutrition, rest and exercise. By taking care of one's body, the young person preserves her/his body for future labour-market demands. In doing this, the governance works through individualised responsibilities seen as governing the whole of the population as a healthy labour reservoir, as population capital (cf. Prasad, 2009).

The third area of investment in human capitalisation of young people concerns their skills. The emphasis is on skills that are general and adaptable to different fields of employment and life. Interestingly, these skills are best understood in terms of what they are not: technical, practical skills belonging to specific areas. They are skills of self-knowledge and self-management. Here the aspirations of the young people often clash with the aims of the system: while, for the youth, the cultivation of specific skills relating to their interest area is motivating, these are not seen as capacities but rather as hindrances that do not enhance their positioning in the shifting needs of the labour market. 
Human capitalisation is essentially a project that never finishes; the individual is always becoming human capital (Bröckling, 2005). Moreover, the relation between the subject and her/his human capital is speculative, rather than possessive (Feher, 2009). These characteristics highlight the promise-like nature of human capitalisation. According to this logic the young people should strive to constantly maintain their potentiality (see also Mäkinen, 2016). Securing a place in education or employment is not as important as cultivating oneself to constantly become, preserve, maintain and train. It is about investing in one's own human capital (Feher, 2009). The neoliberal 'making live $[\ldots]$ entails the cultivation of life in order to bring forth its potentials' (Binkley, 2014, p. 72) and operates on futures. Finding a job or a place in education is secondary to this overall shaping of life, as young people are formed into a reservoir of potentiality. As such, the activation measures aimed at the youth reflect the all-encompassing nature of human capitalisation developed by Chicago School economists. We suggest that one of the key clashing points between the youth and the activation services is, however, precisely this: the youth want to work for something they consider achievable, a particular kind of job or a place in education they are interested in and want to pursue further. For them, it is illogical to cultivate oneself as a potentiality for all time. According to the rationale of the youth, the reward side of human capital theory is missing in the human capitalisation presented in the activation services and their measures. The original theory of human capital was based on the assumption that human behaviour is economically calculable (Feher, 2009). Consequently, the theory promised to calculate whether investments in education and other public services would bring the expected outcomes or rewards (Lemke, 2001; McNay, 2009). The investments are explicated, but the outcomes remain vague. We argue that this vagueness concerning the rewards is a direct source of conflict as the young people receive no fixed reward (such as a place in employment or education, or even concrete advice about how to proceed) but, instead, different exercises and expectations for how to work on themselves for no apparent purpose. While the outcomes or rewards might be detectable from the side of the labour market, this is not so from the side of the youth. Through different measures, human capitalisation works on cultivating the youth to provide for a potentiality for the labour market. In return, however, there is no guarantee that their own desires will be met or even recognised. 


\section{Notes}

1. This article is part of the research project Migrant Youth Employment: Politics of Recognition and Boundaries of Belonging (2014-2017) funded by Kone Foundation, Emil Aaltonen Foundation and Helsinki University 3-year fund.

2. Indicative of the continuous transformation of the activation field, guidance was a project by the City of Helsinki that no longer exists.

\section{References}

Adamson, M. (2009). The human capital strategy. Ephemera, 9(4): 271-284.

Adkins, L. (2012). Out of work or out of time? Rethinking labor after the financial crisis. South Atlantic Quarterly, 111(4), 621-641.

Arts, J. \& Van den Berg, M. (2018). Pedagogies of optimism: Teaching to 'look forward' in activating welfare programmes in the Netherlands. Critical Social Policy, Online First.

Becker, G. S. (1962). Investment in Human Capital: A Theoretical Analysis. Journal of Political Economy, 70(5): 9-49.

Bengtsson, A. (2011). European policy of career guidance: the interrelationship between career selfmanagement and production of human capital in the knowledge economy. Policy Futures in Education, 9(5): 616-627.

Binkley, S. (2014). Happiness as Enterprise. An Essay on Neoliberal Life. New York: State University of New York Press.

Boland, T. (2016). Seeking a role: disciplining jobseekers as actors in the labour market. Work, Employment and Society, 30(2), 334-351.

Bowsher, J. (2018). Credit/debt and human capital: financialized neoliberalism and the production of subjectivity. European Journal of Social Theory, Online First. 
Brady, M. (2011) Researching governmentalities through ethnography: the case of Australian welfare reforms and programs for single parents. Critical Policy Studies, 5(3): 264-282.

Brady, M. (2018). Targeting single mothers? Dynamics of contracting Australian employment services and activation policies at the street level. Journal of Social Policy, 47(4): 827-845.

Brown, W. (2015). Undoing the Demos. Neoliberalism's Stealth Revolution. New York: Zone Books.

Bröckling, U. (2005). Gendering the enterprising self. Distinktion: Scandinavian Journal of Social Theory, 6(2), 7-25.

Clarke, J. (2005) New Labour's citizens: activated, empowered, responsibilized, abandoned? Critical Social Policy, 25(4), 447-463.

Davies, W. (2014). Neoliberalism: A bibliographical review. Theory, Culture \& Society, 31(7-8), 309-317.

De La Fabián, R. \& Stecher, A. (2017). Positive psychology's promise of happiness: A new form of human capital in contemporary neoliberal governmentality. Theory \& Psychology, 27(5): 600-621.)

Feher, M. (2009). Self-Appreciation; or, The Aspirations of Human Capital. Public Culture, 21(1), 21-41.

Folles $\varnothing$, R. (2015). Youth at Risk or Terms at Risk? Young, 23(3), 240-253.

Foucault, M. (1985). The Use of Pleasure. Volume 2 of The History of Sexuality. New York: Pantheon Books.

Foucault, M. (2010) The birth of biopolitics: Lectures at the Collège de France 1978-1979. Palgrave Macmillan.

Furlong, A. (2006). Not a very NEET solution. Representing problematic labour market transitions among early school-leavers. Work, Employment and Society, 20(3), 553-569. 
Gane, N. (2014). The emergence of neoliberalism: Thinking through and beyond Michel Foucault's lectures on biopolitics. Theory, Culture \& Society, 31(4), 3-27.

Gordon, C. (1991). Governmental rationality: an introduction. In G. Burchell, C. Gordon, \& P. Miller (Eds.), The Foucault Effect: Studies in Governmentality (pp. 1-52). Chicago, IL: University of Chicago Press.

Haikkola, L.; Näre, L. \& Lähteenmaa, J. (2017). Tunnistamisen institutionaaliset kontekstit: Nuoret työttömät aktivointitoimenpiteissä [The institutional context of recognition. Unemployed youth in activation measures]. Aaltonen, S. \& Kivijärvi, A. (eds) Nuoret aikuiset hyvinvointipalvelujen käyttäjinä ja kohteina. Helsinki: Nuorisotutkimusseura, pp. 53-78.

Kelly, P (2006). The Entrepreneurial Self and 'Youth at-risk': Exploring the Horizons of Identity in the Twenty-first Century, Journal of Youth Studies 9(1), 17-32.

Lemke, T. (2001). 'The birth of bio-politics': Michel Foucault's lecture at the Collège de France on neo-liberal governmentality. Economy \& Society, 30(2), 190-207.

McDonald, C. \& Marston, G. (2005). Workfare as welfare: governing unemployment in the advanced liberal state. Critical Social Policy, 25(3), 374-401.

McNay, L. (2009). Self as enterprise: Dilemmas of control and resistance in Foucault's The Birth of Biopolitics. Theory, Culture \& Society, 20(6), 55-77.

Mäkinen, K. (2016). Valuable selves: Potentiality and temporality in work-related coaching. European Journal of Cultural Studies 19(1), 69-86.

Newheiser, D. (2016). Foucault, Gary Becker and the critique of neoliberalism. Theory, Culture \& Society, 33(5), 3-21.

Newman, J. (2007). The "double dynamics" of activation. Institutions, citizens and the remaking of welfare governance. International Journal of Sociology and Social Policy, 27(9/10), 364-375. 
Prasad, A. (2009) Capitalizing disease: Biopolitics of drug trials in India. Theory, Culture \& Society, 26(5): 1-29.

Rose, N. (1998). Inventing Ourselves: Psychology, Power, and Personhood. Cambridge: Cambridge University Press.

Rose, N. (1999). Governing the soul: the shaping of the private self (2nd). London: Free Associations Books.

Scharff, C. (2016). The psychic life of neoliberalism: Mapping the contours of entrepreneurial subjectivity. Theory, Culture \& Society, 33(6), 107-122.

Sharone, O. (2007). Constructing unemployed job seekers as professional workers: The depoliticizing work-game of job searching. Qualitative Sociology, 30(4), 403-16.

Tan, E. (2014) Human capital theory: a holistic criticism. Review of Educational Research, 84(3): $411-445$.

Van Oort, M. (2015). Making the neoliberal precariat: Two faces of job searching in Minneapolis. Ethnography, 16(1), 74-94.

Woronov, T.E. (2012). Doing time: Mimetic labor and human capital accumulation in Chinese vocational schools. The South Atlantic Quarterly 111(4), 701-719. 